\title{
Self-Reported and Objectively Measured Physical Activity of Elderly Mans from Bar
}

\author{
Milos Kovacevic ${ }^{1}$ \\ 'University of Montenegro, Faculty for Sport and Physical Education, Niksic, Montenegro
}

\begin{abstract}
We did a research with a sample of 100 male respondents from Bar. A standardized IPAQ questionnaire was used as the instrument of the research, in order to find out the amount of physical activity for people aged between 50 and 69 years. From that number of respondents, 63 respondents was between 50 and 59 years, and 37 respondents between 60 and 69 years. The questionnaire consists questions about physical activity on work, in transport, at home, and during free time. The research results have shown that respondents of both groups have a low level of physical activity in transport, by the younger group 429,81MET, and by the older group 571,38MET. The same level of activity is present for free time activity by the younger group 546,2MET. A moderate physical activity are represented for free time activities by the older group 927,3MET. All the other aspects of physical activities are represented on a high level, by both groups. By comparing these two subsamples with a t-test (level of significance 0,01 ), it has been established that there is a statistically significant difference between these results, except for the total moderate intensity activities.
\end{abstract}

Key words: Physical Activity, 50-69 Years, Male, IPAQ Questionnaire

\section{Uvod}

Pod pojmom fizičke aktivnosti obično se podrazumijeva oblik rekreativne ili organizovane tjelesne aktivnosti koja se uglavnom sprovodi u okvirima programa ili pod stručnim vođstvom, a s ciljem unapređenja zdravlja, tjelesnog statusa i opšte dobrobiti za pojedinca (Bungić i Barić, 2009).

U savremenom dobu došlo je do naglog pada fizičke aktivnosti kod kompletne populacije. Djeca se sve više služe tehnologijom, te zanemaruju tradicionalne načine igre, a ne smije se zaboraviti da igra predstavlja slobodnu, nagonsku, spontanu, neproizvodnu i prijatnu aktivnost koja na mnogo načina pozitivno utiče na razvoj organizma (Bjelica, 2005; Bjelica i Krivokapić, 2011). Odrasli koriste tehnologiju kao veliku olakšicu svakodnevnom životu. $\mathrm{U}$ ovome treba tražiti razlog za gore navedeni problem.

Zbog ovakve pojave u poslednjih nekoliko decenija kontinuirano opada radna sposobnost i ljudsko društvo nazaduje, kako u intelektualnom tako i u fizičkom razvoju. Srijećemo se sa sve većim procentom gojaznih, ljudi sa tjelesnim deformite- tima ili pak nekim još ozbiljnijim bolestima kao što su bolesti srca, dijabetes i tome slično. Ovaj podatak je veoma zabrinjavajući, ali nije iznenađenje, s obzirom na to da je poznato da je kroz kompletan period evolucije čovjek zavisio upravo od fizičke aktivnosti koja mu je pružala mogućnost da živi, radi i stvara. Međutim, sada kada je to promijenjeno i savremeni način života od čovjeka ne zahtijeva fizički napor, a tehnologija guši čovjeka primoravajući ga da bude neaktivan koristeći je u obavljanju radnih zadataka susrijećemo se sa navikama za koje možemo reći da su zaostavština iz prošlosti. Ovo se može objasniti time što je kretanje duboko utisnuto u čovjekov genetski kod, te se ljudski organizam može posmatrati kao mašina koja ne može funkcionisati bez fizičke aktivnosti. S obzirom da je fizičke aktivnosti sve manje i "mašina" se polako "kvari", a "kvar" se manifestuje gore navedenim problemima koji se najčešće odražavaju na zdravlje.

Fizička aktivnost se definiše kao svaki oblik tjelesnog pokreta proizveden skeletnim mišićima koji izaziva utrošak energije. Fizička neaktivnost se smatra najvažnijim javnim

Correspondence:

Montenegro M. Kovacevic

Gport University of Montenegro, Faculty for Sport and Physical Education, Narodne omladine bb, 81400 Niksic, Montenegro E-Mail: mkocho994@gmail.com 
zdravstvenim problemom modernog društva. Generalno, poznato je da je fizička neaktivnost povezana sa različitim oblicima hroničnih bolesti, kao što su konorarna bolest arterije, srčani udar, hipertenzija, kancer, kancer dojke, dijabetes, osteoporoza.

Iz svega gore navedenog izvodi se zaključak da je nužno baviti se fizičkom aktivnošću bez obzira na godine. Kod djece potreba i navika za fizičkom aktivnošću formira se putem fizičkog vaspitanja.

Fizičko vaspitanje predstavlja, prema jednoj od savremenih definicija, dio opšteg vaspitanja i predstavlja svjesni, planski, sistematski, organizovan proces, koji putem fizičkog vježbanja ostvaruje zadatke postavljene u cilju stvaranja svestrano i hramonično razvijene ličnosti (Bjelica i Krivokapić, 2010).

Pogrešan je stav da ljudi starije dobi ne treba da upražnjavaju fizičke aktivnosti kako bi sačuvali organizam. Upravo je suprotno, treba da upražnjavaju fizičke aktivnosti jer im one mogu donijeti samo poboljšanja, naravno ako se sprovode planski. Fizička aktivnost je važno sredstvo za smanjenje hroničnih bolesti, a takođe je i snažan faktor koji može pomoći starijim ljudima da se integrišu u društvo. Zajednička fizička aktivnost u grupama pomaže starijim ljudima da se upoznaju sa drugima, prošire svoju društvenu mrežu i poboljšaju svoje zdravlje (Popović i Bjelica, 2017). Fizička aktivnost ima veliki uticaj na socijalizaciju starijih, zapravo može služiti za smanjenje socijalne isključenosti starijih ljudi, proširenje društvene mreže i poboljšanje njihovog zdravlja (Popović i Bjelica, 2017). Takođe fizička aktivnost u starijem dobu omogućava zadovoljenje različitih motiva. Jedan od onih koji se najčešće javlja kod starijih osoba jeste afilijativni motiv, odnosno težnja za druženjem (Bjelica, 2006a; 2006b).

Starenje je prirodan proces koji se ne može zaustaviti, ali se može uticati na zdravlje čovjeka i što duže održavanje homeostaze organizma, i to putem fizičke aktivnosti. Benefiti od fizičke aktivnosti za starije su višetruke: redovna fizička aktivnost smanjuje rizik od kardiovaskularnih bolesti, kancera i demencije. Starija lica mogu ostati nezavisna i smanjiti šanse od pada sposobnosti što je od velikog značaja za starije. Starije osobe bi trebale biti dnevno aktivne od 15-30 do 40 minuta (Radoševoć, Mihok, Puljak, Perk i Roksandić, 2006).

Program vježbanja treba da bude usmjeren na one djelove koji su najviše podložni degenerativnim promjenam i povredama. To su kičma, kukovi, koljena i ramena. Takav program bi sadržao vježbe snage, fleksibilnosti, izdržljivosti. Intenzitet izabranog programa bi trebao biti prilagođen kondiciji pojedinca, jer bi preopterećenje izazvalo ozbiljnije povrede. Naravno fizičke aktivnosti se u ovom dobu većinom upražnjavaju putem rekreacije.

Sportska rekreacija je slobodno izabrana, a ne nametnuta aktivnost, koja je usmjerena na zadovoljenje osnovnih ljudskih potreba i kroz raznovrsne, svima dostupne sportsko-rekreativne aktivnosti, koje su usaglašene sa zdravstvenim statusom, nivoom opštih sposobnosti, polnim i uzrasnim karakteristikama svakog pojedinca (Bjelica, 2002; 2004).

Kada konačni oblik kretanja nije poznat, postoji način da se njegove performanse izračunaju. Poznato je da je svako složeno kretanje samo posljedica određenog djelovanja određenih sila. Za kvantitativno utvrđivanje tih uzoraka odnosno sila, koriste se odgovarajući uređaji koji su razvojem elektronike sve raznovrsniji i precizniji (Bjelica, 2013, Bjelica i Fratrić, 2011). Dakle savremena tehnologija nam omoguća- va konstantno praćenje kako oblika, tako i intenziteta kretanja što omogućava optimalno doziranje kod osoba starije životne dobi.

Sve gore navedeno navelo nas je na ovo istraživanje. Cilj ovog istraživanja bio je utvrditi da li se i u kom obimu, osobe muškog pola, treće životne dobi na teritoriji opštine Bar, bave fizičkom aktivnošću.

\section{Metod}

Samoprocjena fizičkih aktivnosti osoba muškog pola od 50 do 69 godina izvršena je međunarodnim IPAQ upitnikom-International Physical Activity Questionnaires (Brown \& Miller, 2005; Azevedo et al., 2007).

IPAQ upitnik procjenjuje fizičku aktivnost u više domena: fizičke aktivnosti na poslu, fizičke aktivnosti u prevozu, fizičke aktivnosti u dvorištu i kući, i fizičke aktivnosti u slobodnom vremenu. Dostupan je u dužoj i kraćoj verziji. Prilikom ovog istraživanja, korišćena je duža forma upitnika, koja sadrži 31-o pitanje. Ova verzija je napravljena da obezbijedi obimnu procjenu dnevnih fizičkih aktivnosti i da utvrdi vrijeme koje se provede tokom hodanja, prilikom obavljanja aktivnosti umjerenog i visokog inteziteta na poslu, u prevozu, obavljanju poslova u kući i dvorištu i aktivnostima u slobodnom vremenu. Prema ovom upitniku, predložena su tri nivoa fizičke aktivnosti: niska, umjerena i visoka. Izvršeno je računanje za svaku stavku posebno (teške aktivnosti, umjerene aktivnosti i hodanje) prema IPAQ uputstvu, kako bismo odredili vrijeme fizičke aktivnosti ispitanika tokom jedne nedjelje u odnosu na težinu aktivnosti koje su oni sprovodili. Takođe, izvršeno je izračunavanje Metabolic Equivalent Task (MET) za svaki tip fizičke aktivnosti posebno (posao, prevoz, domaćinstvo i slobodno vrijeme). MET je jedinica vrijednosti koja pokazuje nivo utrošene energije tokom neke aktivnosti. Jedna MET jedinica odgovara nivou energije koji je dovoljan za funkcionisanje organizma u mirovanju, odnosno dovoljan za održavanje bazalnog metabolizma. MET jedinice se koriste kao univerzalno sredstvo procjene nivoa fizičkih aktivnosti, kako bi se jednostavnije mogli donositi zaključci na velikom broju uzoraka. Ukupni nedeljni nivo fizičke aktivnosti (MET-min/week) dobijen je pojedinačnim zbrajanjem MET vrijednosti za svaku stavku. Kod teških i umjerenih aktivnosti uzete su u obzir samo one koje su trajale najmanje deset minuta u kontinuitetu. Za izračunavanje MET vrijednosti korišćeni su sljedeći koeficijenti: Naporne fizičke aktivnosti $=8.0$ METs, Umjerene fizičke aktivnosti $=4.0$ METs i Hodanje $=3.3$ METs. MET vrijdnost se dakle izračunava tako što ukupno vrijeme u kojem se obavlja aktivnost pomnožimo sa datim koeficientima. Visoku fizičku aktivnost obavljaju osobe koje obavljaju izrazito naporne fizičke aktivnosti najmanje 3 dana nedjeljno i najmanje 1500 minuta nedjeljno. Umjerenu fizičku aktivnost obavljaju osobe koje obavljaju 20 minuta dnevno i najmanje 3 dana naporne fizičke aktivnosti ili 5 dana po 30 minuta umjerenih fizičkih aktivnosti i hodanja ili 7 dana kombinacije šetnje, umjerenih i napornih aktivnosti. Osobe koje ne ispunjavaju nijedan od ovih kriterijuma, nedovoljno su fizički aktivne. Za obradu podataka primijenjena je deskriptivna statistika odnosno standardna devijacija kojom su prikazani IPAQ parametri MET vrijednosti. Za utvrđivanje statistički značajnih razlika u nivou fizičkih aktivnosti između dva sub-uzorka korišćena je diskriminativna statistika, odnosno t-test na nivou značajnosti $\mathrm{q}=0.01$. 


\section{Rezultati}

Uzorak ispitanika u okviru istraživanja sačinjavalo je 100 osoba muškog pola, starosti od 50 do 69 godina iz Bara i okolnih mijesta. Uzorak je podijeljen na dva sub-uzorka (tabela 1), po kriterijumu hronološke starosti, pri čemu su jedan subuzorak čine osobe starosti od 50 do 59 godina (63), a drugi osobe starosti od 60 do 69 godina (37). Od ukupnog broja ispitanika, njih 78 je zaposleno, dok je 22 ispitanika nezaposleno ili je $\mathrm{u}$ penziji. Od toga broja, 11 njih pripada sub-uzorku od 50 do 59 godina, dok 11 osoba pripadaju sub-uzorku od 60 do 69 godina. Takođe je bitno naglasiti da određeni broj ispitanika živi u prigradskim područjima Bara.

Tabela 1. Uzorak ispitanika

\begin{tabular}{ccc}
\hline Godine starosti & Broj & Procenat (\%) \\
\hline $50-59$ & 63 & $63 \%$ \\
$60-69$ & 37 & $37 \%$ \\
Ukupno & 100 & $100 \%$ \\
\hline
\end{tabular}

U tabeli 2. prikazani su rezultati aktivnosti koje su ispitanici obavljali u posljednjih sedam dana. Rezultati pokazuju koliki je ukupan iznos njihovih aktivnosti (hodanja, umjerenih i napornih aktivnosti) na poslu, aktivnosti u prevozu (vožnja biciklom i hodanje u svrhu prevoza), aktivnosti u dvorištu i kući (napornih i umjerenih aktivnosti) i aktivnosti u slobodnom vremenu (napornih i umjerenih aktivnosti, hodanje $u$ slobodnom vremenu). Takođe, prikazana je i statistički značajna razlika u nivou aktivnosti koja se javlja među grupama.

Tabela 2. Aktivnosti koje su ispitanici obavljali u poslednjih sedam dana

\begin{tabular}{lccc}
\hline & $\mathbf{5 0 - 5 9}$ & $\mathbf{6 0 - 6 9}$ \\
$\mathbf{n = 3 7}$ & $\mathbf{q}$ \\
\hline Ukupne aktivnosti na poslu (MET) & $\mathbf{n = 6 3}$ & $4214,95 \pm 585,59$ & 0.00 \\
Ukupne aktivnosti u prevozu (MET) & $9635,9 \pm 1481,82$ & $571,38 \pm 235,69$ & 0.00 \\
Ukupne aktivnosti u dvorištu i kući (MET) & $429,81 \pm 300,90$ & $1530,23 \pm 358,97$ & 0.00 \\
Ukupne aktivnosti u slobodnom vremenu (MET) & $1783,87 \pm 201,22$ & $927,33 \pm 220,31$ & 0.00 \\
Ukupno hodanje (MET) & $546,2 \pm 158,15$ & $2018,62 \pm 880,65$ & 0.00 \\
Ukupne aktivnosti umjerenog inteziteta (MET) & $2778,15 \pm 937,67$ & $3617,44 \pm 1020,33$ & 0.02 \\
Ukupne izrazito naporne aktivnosti (MET) & $3579,32 \pm 1376,77$ & $3029,29 \pm 1048,50$ & 0.00 \\
Ukupan rad (MET) & $1774,88 \pm 2608,20$ & $7243,89 \pm 1650,79$ & 0.00 \\
\hline
\end{tabular}

MET- metabolički ekvivalent; n- broj ispitanika; q- statistički značajna razlika utvrđena t-testom

Iz priložene tabele može se vidjeti da je najveća aktivnost zapažena na poslu i kod jednog i kod druge starosne grupe. Kod mlađe grupe 9635,9 MET, dok kod starije grupe iznosi 4214,95 MET i ove aktivnosti su na vrlo visokom nivou. Kada je riječ o aktivnostima u prevozu kod obije grupe, aktivnost je na niskom nivou; odnosno kod mlađe gupe 429,81 MET dok je kod starije grupe 571,38 MET. Obije grupe imaju visok nivo aktivnosti kada su u pitanju aktivnosti u dvorištu i kući, i to osobe od 50 do 59 godina 1783,87 MET, dok osobe od 60 do 69 godina imaju 1530,23 MET. Kada je u pitanju aktivnost u slobodno vrijeme kod mlađe grupe, ona je na niskom nivou i iznosi 546,2 MET međutim kod starije grupe aktivnost je nešto viša i na umjerenom je nivou sa vrijednošću od 927,33 MET. Obije grupe takođe imaju visok nivo aktivnosti kada je u pitanju ukupno hodanje, i to mlađa grupa 2778,15 MET, a starija grupa 2018,62 MET. Visok nivo aktivnosti uočen je kada su u pitanju ukupne aktivnosti umjerenog intenziteta i to mlađa grupa 3579,32 MET, a starija grupa 3617,44MET. I na kraju, kada su u pitanju ukupne izrazito naporne aktivnosti obije grupe takođ imaju visok nivo aktivnosti i to mlađa grupa 1774,88 MET, a starija grupa 3029,29 MET.

Kada se sagleda cjelokupna situacija, i u obzir uzmu svih osam parametara za procjenu fizičke aktivnosti, statističkom obradom podataka, na osnovu $\mathrm{t}$ - testa možemo zaključiti da postoji statistički značajna razlika na nivou 0.01 kod čak sedam ispitivanih kategorija. Jedino to nije slučaj kada upoređujemo umjerene fizičke aktivnosti ovih ispitivanih uzoraka.

\section{Diskusija}

Svjetska zdrastvena organizacija, kao faktor prevencije različitih bolesti, predlaže da se umjerene fizičke aktivnosti i hodanje obavljaju od $4000 \mathrm{MET}$ minut/nedjelja do 10000 MET minut/nedjelja, ili obavljanje izrazito napornih fizičkih aktivnosti od $600 \mathrm{MET}$ minut/nedjelja do $4000 \mathrm{MET}$ minut/ nedjelja.

Ukoliko uporedimo vrijednosti ovog istraživanja sa vrijednostima MET minut/nedjelja koje predlaže Svjetska zdravstvena organizacija, možemo zaključiti da kada su u pitanju umjerene aktivnosti, dobijeni rezultati govore da ukupne aktivnosti umjerenog intenziteta ovog istraživanja približno ispunjavaju minimum koji predlaže ova institucija. Kada je u pitanju ukupno hodanje, dobijeni rezultati, pak, ne ispunjavaju standarde koje propisuje Svjetska zdravstvena organizacija, ali zato u parametru izrazito napornih fizičkih aktivnosti rezultati ovog istraživanja čak i nadmašuju predložene parametre.

Milanović i saradnici (2012) odradili su istraživanje sa primarnim ciljem upoređivanja nivoa tjelesnih aktivnosti kod osoba starijih od 60 godina i dobijeni rezultati ukazuju da je umjerena fizička aktivnost najdominantnija u odnosu na ostale ispitivane vidove aktivnosti. Mitrović (2018) sprovela je slično istraživanje sa ciljem da se utvrdi da li se i u kojoj mjeri osobe muškog pola treće dobi bave fizičkom aktivnošću. Istraživanje je sprovedeno na teritoriji opštine Nikšić. Rezultati ovog istraživanja govore da je prisutan visok nivo fizičke aktivnosti na poslu, izrazito napornih fizičkih aktivnosti, kao i ukupnog hodanja. Kada su u pitanju ukupne aktivnosti umjerenog in- 
tenziteta, u ovom istraživanju kod mlađe grupe one su na visokom nivou dok su kod starije grupe na umjerenom nivou. Aktivnosti u prevozu su kod mlađe grupe na umjerenom, dok su kod starije grupe na niskom nivou. Aktivnosti sprovedene u slobodno vrijeme su kod obije grupe na umjerenom nivou, dok su aktivnosti u dvorištu i kući na niskom nivou. Upoređujući rezultate datog istraživanja sa rezultatima ovog istraživanja može se konstatovati da su u parametrima koji se tiču fizičke aktivnosti na poslu, fizičke aktivnosti umjerenog intenziteta, aktivnosti ukupnog hodanja i izrazito naporne aktivnosti, rezultati slični, odnosno aktivnost je na visokom nivou i kod muškaraca iz Bara i Nikšića trće dobi. U ostalim parametrima se razlikuju jer su u ovom istraživanju gotovo svi rezultati na visokom nivou izuzev aktivnosti u prevozu, dok su ostali parametri kod datog istraživanja na umjerenom ili niskom nivou.

Takođe na ovu temu biće sprovedena dva vrlo bitna istraživanja u okviru nacionalnog projekta pod naslovom „Efekti fizičke aktivnosti u socijalnoj inkluziji starijih ljudi”, koji je odobrilo Ministarstvo nauke u Crnoj Gori, u njima će biti predstavljen nivo fizičkih aktivnosti starijih muškaraca kao i starijih žena u Crnoj Gori (Popović, Bjelica, Vukotić i Mašanović, 2018; Mašanović, Vukotić, Bjelica i Popović, 2018).

Biološkim procesom starenja snižava se nivo tjelesnih funkcija čovjeka. Biološke promjene ugledaju se u smanjenoj radnoj sposobnosti, bržem zamaranju, te sporijem oporavku nakon tjelesnih aktivnosti. Takođe, osobe u trećoj životnoj dobi imaju slabije držanje, odnosno posture tijela. Naime, biološkim procesom starenja usporavaju se metaboličke funkcije organizma, te opada nivo aerobnog kapaciteta. (Bajramović, Likić, Manić i Mekić, 2015.

Efekti sistematskih fizičkih aktivnosti na mišićni sistem odraslih koji stare su impresivni, i rezultat dobro planiranog, naučno zasnovanog programa treninga otpora i snage. Od svih sistema tijela, neuromuskularni sistem može demonstrirati najvidljivije dramatične razlike između kompletno neaktivne osobe i osobe koja konstantno trenira u svim životnim dobima. U velikom broju istraživanja je potvrđeno da starije osobe koje ostanu fizički aktivne imaju veće nivoe snage nego sedentarne osobe, što sve upućuje na povezanost fizičke aktivnosti i psihomotornih funkcija kod starijih (Bjelica, Krivokapić, 2012).

Imajući u vidu ovakve podatke, treba istaći nesumnjiv značaj ovog istraživanja u mnogim aspektima. Prije svega, ovim istraživanjem stiče se uvid u nivo fizičke aktivnosti osoba trećeg doba na teritoriji opštine Bar, ali ako se u obzir uzmu i ostali rezultati sličnih istraživanja na teritorijama ostalih opština Crne Gore može se sumiranjem kompletnih rezultata steći uvid u nivo fizičke aktivnosti osoba trećeg doba na uzorku dovoljne veličine, tako da se može izvršiti generalizacija na nivou kompletne populacije. Osim toga, ovo istraživanje kod određenog broja ljudi koji su učestvovali u njemu može probuditi želju kako za učestvovanjem u fizičkim aktivnostima, tako i za edukacijom o fizičkoj aktivnosti, njenoj pravilnoj primjeni i korisnim efektima.

Iz navedenih rezultata možemo zaključiti da je prisutan zadovoljavajući nivo fizičkih aktivnosti kada je u pitanju starija grupa, odnosno osobe od 60 do 69 godina starosti. Kod drugog dijela uzorka, označenog kao mlađa grupa, odnosno osobe od 50 do 59 godina, rezultati su takođe na zadovoljavajućem nivou. Jedini parametar koji nije na zadovoljavajućem nivou kod obije grupe, kao što je rečeno, je aktivnost u prevozu. Određenu specifičnu notu ovim podacima daje činjenica da je ne mali broj ispitanika nastanjen u prigradskim i seoskim područjima, gdje sam način života diktira upražnjavanje fizičkih aktivnosti. Rezultati ovog istraživanja pokazuju nam da je situacija kod osoba trećeg doba zadovoljavajuća. Međutim, stiče se utisak da ovi rezultati odaju stanje koje je promjenljivo. Sada novi naraštaji sve manje upražnjavaju fizičke aktivnosti. Ako uzmemo u obzir činjenicu da djeca uče upravo na primjeru svojih roditelja pa i ostalih članova porodice, a na poslijetku i okoline, može se ocjeniti kao obećavajući nivo fizičke aktivnosti starijih osoba prikazanim u ovom istraživanju. Stoga treba težiti ka tome da svoje stečene navike za fizičkom aktivnošću prenose i na mlađe naraštaje kako bi se ispravila situacija koja prijeti da u novijem dobu postane trend, a to je sve manja zastupljenost fizičke aktivnosti koja povlači za sobom razne bolesti i poremećaje u razvoju kao i načinu ponašanja djece i omladine.

\section{Acknowledgements}

There are no acknowledgements.

\section{Conflict of Interest}

The authors declare that there are no conflict of interest.

Received: 01 January 2018| Accepted: 28 March 2018 | Published: 13 July 2018

\section{References}

Azevedo, M., Araujo, C., Reichert, F., Siqueira, F., Da Silva, M., \& Hallal, P. (2007). Gender differences in leisure-time physical activity. International journal public health, 52(1), 8-15.

Bajramović, I., Likić, S., Manić, G. i Mekić, A., (2015). Dizajniranje savremenog kondicionog treninga. Fakultet sporta i tjelesnog odgoja, Sarajevo: Univerzitet u Sarajevu.

Bjelica, D. (2002). Opšti pojmovi sportskog treninga: (skraćena verzija). Podgorica: Crnogorska sportska akademija.

Bjelica, D. (2004). Uticaj sportskog treninga na antropomotoričke sposobnosti: (fudbalskih kadeta Crne Gore). Podgorica: Crnogorska sportska akademija.

Bjelica, D. (2005). Sistematizacija sportskih disciplina i sportski trening. Podgorica: Crnogorska sportska akademija.

Bjelica, D. (2006a). Sportski trening. Podgorica: Crnogorska sportska akademija.

Bjelica, D. (2006b). Teorijske osnove tjelesnog i zdrastvenog obrazovanja. Podgorica: Crnogorska sportska akademija.

Bjelica, D. (2013). Teorija sportskog treninga. Podgorica: Crnogorska sportska akademija.

Bjelica, D., i Fratrić, F. (2011). Sportski trening: teorija, metodika i dijagnostika. Nikšić: Fakultet za sport i fizičko vaspitanje.

Bjelica, D., i Krivokapić D. (2012). Uticaj fizičkog vježbanja na psihomotorne funkcije starijih osoba. Zbornik radova Druge međunarodne konferencije Sportske nauke izdravlje, Banja Luka: Panaevropski univerzitet APEIRON, 191-96.

Bjelica, D., i Krivokapić, D. (2010). Teorijske osnove fizičke kulture. Nikšić: Fakultet za sport i fizičko vaspitanje Univerziteta Crne Gore

Bjelica, D., i Krivokapić, D. (2011). Teorija igre. Nikšić: Fakultet za sport i fizičko vaspitanje Univerziteta Crne Gore.

Brown, W., \& Miller, Y. (2005). International differences in management of physical activity data: can they explain some of the differences in prevelence estimates. Journal of Physical activity and Health, 2(4), 460-9.

Bungić M., i Barić R. (2009), Tjelesno vježbanje i neki aspekti psihološkog zdravlja. Hrvatski športskomedicinski vjesnik, 24(2), 65-75.

Masanovic, B., Vukotic, M., Bjelica, D., \& Popovic, S. (2018). Describing Physical Activity Profile of Older Montenegrin Males Using the International Physical Activity Questionnaire (IPAQ). In Book of Abstracts 15th International Scientific Conference on Transformation Process in Sport "Sport Performance" (61), Podgorica: Montenegrin Sports Academy.

Milanović, Z., Pantelić, S., Sporiš, G., Krakan, I., i Mudronja, L. (2012). Razlike u nivou tjelesne aktivnosti kod muškaraca i žena preko 60 godina starosti. 21. ljetnja škola kineziloga republike Hrvatske, 21, 163-8.

Milanović, Z., Pantelić, S., Sporiš, G., Krakan, I., \& Mudronja, L. (2012). Razlike u nivou tjelesne aktivnosti kod muškaraca i žena preko 60 godina starosti. Zbornik radova 21. ljetne škole kineziologa Republike Hrvatske "Intenzifikacija procesa vježbanja u područjima edukacije, sporta, sportske rekreacije i kineziterapije" (163-168). Zagreb: Hrvatski kineziološki savez. 
Mitrovi, M. (2018). Self-Reported and Objecitevly Meastured Physical Activity of Males from 50 to 69 years old. Journal Anthropology of Sport and Physical Education, 2(2), 99-101.

Popovic, S., Bjelica, D., Vukotic, M., \& Masanovic, B. (2018). Describing Physical Activity Profile of Older Montenegrin Females Using the International Physical Activity Questionnaire (IPAQ). In Book of Abstracts 15th International Scientific Conference on Transformation Process in Sport "Sport Performance" (60-61), Podgorica: Montenegrin Sports Academy.
Popović, S., i Bjelica, D. (2017). Effects of physical activity on social exclusion among older people: a literature review. In Conference Book of Abstract of the 8th Conference of HEPA Europe "Modern Approaches to Physical Activity promotion and measurement" (122), Zagreb: HEPA Europe.

Radašević H., Mihok D., Puljak A., Perko G., i Roksandić S. (2006), Smjernice za provedbu tjelesne aktivnosti u starijoj životnoj dobi. Hrvatski časopis za javno zdravstvo, 2(7,8) 